12 Ware J, Sherbourne C. The MOS 36 item short-form health survey (SF36). Med Care 1992;30:473-83.

13 Cox JL, Holden J, Sagovsky R. Detection of postnatal depression: development of the 10-item Edinburgh postnatal depression scale (EPDS). Br J Psychiatry 1987;150:782-6.

14 Broadhead WE, Gehlbach SH, De Gruy FV, Kaplan BH. The Duke-UNC functional social support questionnaire measurement of social support in family medicine patients. Med Care 1988;26:709-23.

15 Brazier JE, Harper R, Jones NMB, O'Cathain A, Thomas KJ, Usherwood $\mathrm{T}$, et al. Validating the SF-36 health survey questionnaire: new outcome measures for primary care. BMJ 1992;306;1407-40.

16 Efron B, Tibishirani RJ. An introduction to the bootstrap. New York: Chapman and Hall, 1993.

17 Netten A, Dennett J. Unit costs of health and social care. Canterbury: University of Kent, Personal Social Services Research Unit, 1997.

18 Dennis M, O'Rourke S, Slattery J, Staniforth T, Warlow C. Evaluation of a stroke family care worker: results of a randomised controlled trial. BMJ 1997;314:1071-6.
19 Drummond M, O'Brien B, Stoddart G. Torrence GW. Methods for the economic evaluation of health care programmes. Oxford: Oxford Universit Press, 1997.

20 Oakley A, Rajan L, Grant A. Social support and pregnancy outcome. $\mathrm{Br} J$ Obstet Gynaecol 1990;97:155-62.

21 Oakley A, Hickey D, Rajan L. Social support in pregnancy: does it have long-term effects? J Reprod Infant Psychol 1996;14:7-22

22 Olds DL, Eckenrode J, Henderson CR, Kitzman H, Powers J, Cole R, et al. Long-term effects of home visitation on maternal life course and child abuse and neglect. JAMA 1997;278:637-43.

23 Kitzman H, Olds DL, Henderson CR, Hanks C, Cole R, Tatelbaum R, et al. L Effect of prenatal and infancy home visitation by nurses on pregnancy outcomes, childhood injuries, and repeated childbearing JAMA 1997:278:644-52

24 Houston MJ, Howie PW, Cook A. Do breast feeding mothers get the home support they need? Health Bull 1981;39:166-72.

(Accepted 18 May 2000)

\title{
Cohort study of risk of fracture before and after surgery for primary hyperparathyroidism
}

Peter Vestergaard, Charlotte L Mollerup, Vibe Gedsø Frøkjær, Peer Christiansen, Mogens Blichert-Toft, Leif Mosekilde

Department of Endocrinology and Metabolism, Aarhus University Hospital, Aarhus

Amtssygehus,

Aarhus, Denmark

Peter Vestergaard

research associate

Leif Mosekilde

professor of internal

medicine

Department of

Endocrine Surgery,

Rigshospitalet,

Copenhagen,

Denmark

Charlotte L

Mollerup

consultant in surgery

Vibe Gedsø Frøkjær

medical student

Mogens

Blichert-Toft

professor of surgery

Department of

Surgery, Aarhus

University Hospital

Peer Christiansen

consultant in surgery

Correspondence to:

$P$ Vestergaard,

Osteoporosis Clinic,

Aarhus

Amtssygehus, Tage

Hansens Gade 2,

DK-8000 Århus C,

Denmark

p-vest@post4.

tele.dk

BMJ 2000;321:598-602

\begin{abstract}
Objectives To study whether fracture risk before and after surgery was increased in patients with primary hyperparathyroidism.

Design Cohort study.

Setting Three Danish university hospitals.

Participants 674 consecutive patients with primary hyperparathyroidism (median age 61, range 13-89 years) operated on during the period 1 January 1979 to 31 December 1997; 2021 age and sex matched controls from national patient register.

Main outcome measure Fractures.

Results The cases had an increased relative rate of fractures compared with the controls before surgery $(1.8,95 \%$ confidence interval 1.3 to 2.3$)$ but not after surgery (1.0, 0.8 to 1.3). The risk of fracture was increased for the vertebrae (3.5, 1.3 to 9.7), the distal part of the lower leg and ankles (2.3, 1.2 to 4.3$)$, and the non-distal part of the forearm (4.0, 1.5 to 10.6) before surgery but not after. The increase in risk of fracture began about 10 years before surgery. Risk peaked 5-6 years before surgery and remained raised, although at a lower level, in the five years immediately before surgery. A small increase in risk of fracture of the distal forearm emerged more than 10 years after surgery $(2.9,1.3$ to 6.7$)$.
\end{abstract}

Conclusions Risk of fracture is increased up to 10

years before surgery in patients with primary

hyperparathyroidism. The risk returns to normal after surgery.

\section{Introduction}

Several studies have shown decreased bone mineral content or density in patients with primary hyperparathyroidism. ${ }^{12}$ The reduction varied between skeletal regions, ${ }^{1}$ generally tending towards a higher degree of cortical than trabecular bone loss. After surgical cure of primary hyperparathyroidism, the bone mineral density increases over the first few years in both the forearm ${ }^{3-5}$ and the lumbar spine. ${ }^{56}$ Although a deficit in bone mineral density in the forearm seems to remain, ${ }^{3}$ spinal bone mineral density is usually restored ${ }^{67}$ Long term studies have found a permanent decrease in bone mineral density of the forearm in patients who had ${ }^{7} 8$ and had not ${ }^{9}$ had surgery. A follow up study comparing patients who had had surgery with patients who had not had surgery, showed no difference in forearm bone mineral content after 17 years despite an initial increase in forearm bone mineral content after surgery. ${ }^{3}$ Both groups had lower forearm bone mineral content than control subjects. ${ }^{3}$

Decreased bone mineral density increases the risk of fracture. Several studies have reported an increased prevalence of fractures in patients at the time of diagnosis of primary hyperparathyroidism. ${ }^{10-13}$ The sites at which risk of fracture is increased are the forearm, ${ }^{12}{ }^{13}$ the spine, ${ }^{12}{ }^{14}$ and the femoral neck. ${ }^{12}$ Melton et al reported an increase in fracture risk before, but not after, diagnosis of primary hyperparathyroidism. ${ }^{11}$ In contrast, a large cohort study found no increased risk of hip fractures. ${ }^{15}$ Wilson et al also found no increased risk of vertebral fractures in patients with mild asymptomatic primary hyperparathyroidism. ${ }^{2}$ However, most studies have reported on a limited number of patients ${ }^{10}{ }^{11}$ or have not evaluated the incidence of fracture before and after treatment. ${ }^{10} 12131516$

We conducted a large cohort study in 674 patients who had had surgery for primary hyperparathyroidism at three Danish centres and included 2021 controls to assess the risk of fracture before and after surgery at multiple skeletal sites.

\section{Participants and methods}

A total of 674 patients had had surgery for primary hyperparathyroidism during the period 1 January 1979 to 31 December 1997 at three Danish centres: Rigshospitalet in Copenhagen (1991-7), Aarhus University Hospital (1979-97), and Odense University Hospital (1979-90). The diagnosis was established by 
biochemical tests (raised serum concentrations of parathyroid hormone and calcium) at the regional laboratory and confirmed by histological examination of removed tissue at the regional institute of pathology in collaboration with the surgeon. Data on weight of removed tissue and histological diagnosis were retrieved from the medical files. As serum calcium concentration was measured by different methods at the three centres, serum calcium concentration was expressed as ionised serum calcium measured on the day before surgery. We used the formula

ionised serum calcium $(\mathrm{mmol} / \mathrm{l})=0.25+0.45 \times$

serum total calcium $(\mathrm{mmol} / \mathrm{l})$.

For each of the 674 patients up to three matched control subjects were drawn from population lists of subjects who had been residing in Denmark during the period 1 January 1978 to 31 December 1997. Controls were identified by standard database made by the computer department of the Ministry of the Interior. The control subjects were matched for age (same birth year), sex, and status (living in Denmark, died, or emigrated by 31 December 1997). One case (dead) could be matched with only two control subjects, leaving 2021 control subjects for comparison with the 674 cases. In the controls, the observation period was divided into "before" and "after" surgery according to the date of surgery of the matched case. The matching was maintained in all comparisons of cases and controls-that is, when analysing the time interval more than five years before surgery in cases, the corresponding time in the controls was used, and the number of fractures within that period was counted in both cases and controls.

We obtained from the national patient registry under the National Board of Health ${ }^{17}$ all inpatient or outpatient discharge diagnoses concerning the 674 patients and the 2021 controls between 1 January 1978 and 31 December 1997. We compared the frequency of discharge diagnoses of fracture among cases and controls. The national patient registry covers all discharges from Danish hospitals and thus allows almost complete detection of all fractures with a high validity. ${ }^{17}$ The study had a power of $90 \%$ for detecting a $30 \%$ increase in overall risk of fracture before surgery and a $99 \%$ power for detecting a $40 \%$ increase in overall risk of fracture before surgery. After surgery the corresponding power figures were $59 \%$ for a $30 \%$ increase and $81 \%$ for a $40 \%$ increase.

Mean, standard deviation, median, and range were used as descriptive statistics. Comparisons of incidence were made by relative rates (rate ratios) and Mantel-Haenszel type statistics. We calculated the 95\% confidence intervals of the relative rates using the method of Miettinen: relative rate $\left(1 \pm 1.96 / \sqrt{\chi^{2}}\right)$. If the observed number of fractures was FP in the patients and FC in the controls and the person years at risk TP in the patients and $\mathrm{TC}$ in the controls, then $\mathrm{E}=\mathrm{TP} \times(\mathrm{FP}+\mathrm{FC}) /(\mathrm{TP}+\mathrm{TC})$ and $\mathrm{V}=(\mathrm{FP}+\mathrm{FC}) \times \mathrm{TP} \times$ $\mathrm{TC} /(\mathrm{TP}+\mathrm{TC})^{2}$. Then $\chi^{2}$ was calculated as $(\mathrm{FP}-\mathrm{E})^{2} / \mathrm{V}$. These calculations were performed with Microsoft Excel 5.0 for Windows. Continuous variables were compared by the Mann-Whitney test and contingency tables analysed by the $\chi^{2}$ test. The association between risk factors and fractures before and after surgery among the patients with primary hyperparathyroidism was assessed by Poisson regression. Relative rates
Table 1 Details of cases and matched controls

\begin{tabular}{lccccc} 
Variable & $\begin{array}{c}\text { Female } \\
\text { cases } \\
(\mathbf{n}=\mathbf{5 0 1})\end{array}$ & $\begin{array}{c}\text { Male cases } \\
(\mathbf{n}=\mathbf{1 7 3})\end{array}$ & $\begin{array}{c}\mathbf{P} \\
\text { value* }\end{array}$ & $\begin{array}{c}\text { All cases } \\
(\mathbf{n}=\mathbf{6 7 4})\end{array}$ & $\begin{array}{c}\text { All controls } \\
(\mathbf{n}=\mathbf{2 0 2 1})\end{array}$ \\
\hline Mean (SD) age at surgery (years) & $59.4(14.3)$ & $54.8(16.6)$ & 0.002 & $58.2(15.0)$ & $58.2(15.0)$ \\
\hline Histology (No (\%) of cases): & & & 0.87 & & \\
\hline Adenomas & $451(90)$ & $155(90)$ & & $606(90)$ & - \\
\hline Hyperplasia & $50(10)$ & $18(10)$ & & $68(10)$ & - \\
\hline Mean (SD) weight of removed glands (mg): & $1799(3139)$ & $3032(8794)$ & 0.02 & $2105(5175)$ & - \\
\hline Adenomas & $3603(7091)$ & $3565(4294)$ & 0.13 & $3594(6532)$ & - \\
\hline Hyperplasia & $1.57(0.17)$ & $1.59(0.15)$ & 0.37 & $1.58(0.17)$ & - \\
\hline Mean (SD) serum calcium (mmol/l)† & $109(22)$ & $58(34)$ & 0.002 & $167(25)$ & $15(1)$ \\
\hline No (\%) with previous kidney stones $\neq$ & 109 & & &
\end{tabular}

${ }^{*}$ Comparison of male and female cases.

†lonised serum calcium concentration (upper normal range $1.35 \mathrm{mmol} / \mathrm{l}$ ).

$\ddagger$ At time of surgery (information was missing on one woman).

before and after surgery were compared by Poisson regression. All calculations were performed by using SPSS 6.1.3 for Windows 3.11.

\section{Results}

Table 1 gives details of cases and controls. The male cases were younger and had larger adenomas and a higher frequency of previous kidney stones than the female cases. Among the cases, 97\% (653/674) had surgery less than one year after the first diagnosis of primary hyperparathyroidism was registered. Table 2 shows the risk of fracture before and after surgery. The cases had an increased risk of fractures of the spine, forearms, and lower legs before, but not after, surgery. In both the spine, the forearms, and the lower legs, the increased risk of fracture was present more than one year before surgery. No increased risk of fracture was found at any other site, including the femoral neck. After surgery, cases had no increase in risk of fracture compared with controls. There was a significant reduction after surgery in the relative rate of all fractures together and of forearm fractures.

Table 3 shows that before surgery, only age was related to fracture risk; no association was found with weight of the diseased parathyroid tissue that was removed. Preoperative serum calcium concentration was not associated with the risk of fracture before surgery $(\mathrm{P}=0.99)$.

The figure shows a time resolved curve of total risk of fracture stratified by time before surgery. Before surgery, the crude fracture rate was $15 / 1000$ person years (95\% confidence interval 12 to 17$)$ in cases and 8/1000

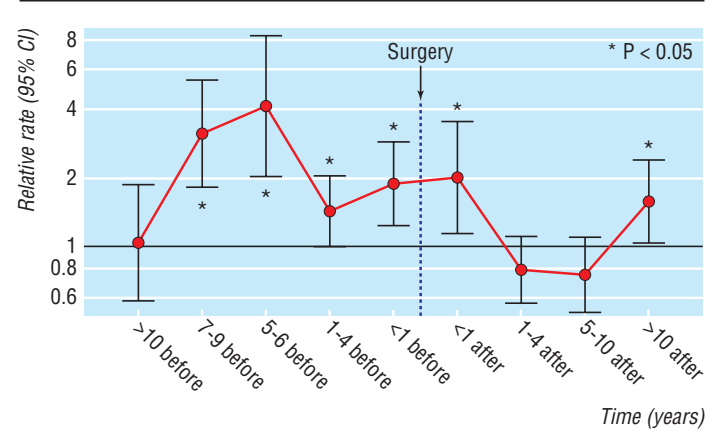

Relative rates and $95 \%$ confidence intervals for risk of fracture in cases compared with matched controls stratified by time before and after surgery. Note the log scale on the ordinate 
Table 2 Relative rates of fractures in cases with primary hyperparathyroidism and matched controls. Before surgery there were 9229.4 observation years among cases and 27670.0 among controls; after surgery there were 3631.5 observation years among cases and 12037.7 among controls

\begin{tabular}{|c|c|c|c|c|c|c|c|}
\hline \multirow[b]{2}{*}{ Fracture site (ICD-8 and ICD-10 codes) } & \multicolumn{2}{|c|}{$\begin{array}{l}\text { No of fractures before } \\
\text { surgery* }^{*}\end{array}$} & \multirow{2}{*}{$\begin{array}{l}\text { Relative rate } \\
(95 \% \mathrm{CI})\end{array}$} & \multicolumn{2}{|c|}{$\begin{array}{l}\text { No of fractures after } \\
\text { surgery }^{\star}\end{array}$} & \multirow{2}{*}{$\begin{array}{l}\text { Relative rate } \\
(95 \% \mathrm{Cl})\end{array}$} & \multirow[b]{2}{*}{$P$ value $\dagger$} \\
\hline & Cases & Controls & & Cases & Controls & & \\
\hline $\begin{array}{l}\text { Skull, face, and jaw (80099, 80100-80109, } \\
80210-80299,80399, \text { S020-S029) }\end{array}$ & $2(8)$ & $7(7)$ & $0.9(0.2$ to 4.1$)$ & $0(0)$ & $1(1)$ & 0 & - \\
\hline $\begin{array}{l}\text { Vertebrae (80500-80599, S120-S129, S220-S221, } \\
\text { S320-S328) }\end{array}$ & $7(11)$ & $6(9)$ & $3.5(1.3$ to 9.7$) \ddagger$ & $3(3)$ & $13(15)$ & $0.8(0.2$ to 2.7$)$ & 0.065 \\
\hline $\begin{array}{l}\text { Upper extremity and clavicles (81099, 81199, } \\
81200-S 81299, \text { S420-S429) }\end{array}$ & $6(7)$ & $15(25)$ & $1.2(0.5$ to 3.1$)$ & $6(9)$ & $29(66)$ & $0.7(0.3$ to 1.6$)$ & 0.39 \\
\hline Forearm (81300-81399, S520-S529) & $19(31)$ & $30(48)$ & $1.9(1.1$ to 3.3$) \ddagger$ & $11(26)$ & $50(100)$ & $0.7(0.4$ to 1.4$)$ & 0.029 \\
\hline Distal forearm (81320-81329, S525, S526) & $11(18)$ & $24(40)$ & $1.4(0.7$ to 2.8$)$ & $10(22)$ & $46(89)$ & $0.7(0.4$ to 1.4$)$ & 0.20 \\
\hline Rest of forearm (81300-81319, S520-S529) & $8(13)$ & $6(8)$ & $4.0(1.5$ to 10.6$) \ddagger$ & $1(4)$ & $4(11)$ & $0.8(0.1$ to 7.4$)$ & 0.20 \\
\hline $\begin{array}{l}\text { Hand (81400-81409, 81500-81509, 81600-81604, } \\
\text { 81899, S620-S628) }\end{array}$ & $6(7)$ & $8(11)$ & $2.2(0.8$ to 6.3$)$ & $3(5)$ & $19(22)$ & $0.5(0.2$ to 1.7$)$ & 0.07 \\
\hline Femur (82000-82009, 82109-82199, S720-S729) & $16(27)$ & $33(76)$ & $1.5(0.8$ to 2.6$)$ & $24(51)$ & $63(145)$ & $1.3(0.8$ to 2.0$)$ & 0.72 \\
\hline Femoral neck $(82000,82001$, S720, S721) & $14(24)$ & $29(64)$ & $1.4(0.8$ to 2.7$)$ & $21(42)$ & $58(125)$ & $1.2(0.7$ to 2.0$)$ & 0.65 \\
\hline Lower leg (82300-82399, 82400-82409, S821-S829) & $19(36)$ & $27(37)$ & $2.1(1.2$ to 3.7$) \ddagger$ & $11(16)$ & $22(40)$ & $1.7(0.8$ to 3.4$)$ & 0.61 \\
\hline $\begin{array}{l}\text { Distal lower leg and ankle (82329, 82400-82409, } \\
\text { S821, S827) }\end{array}$ & $16(31)$ & $21(24)$ & $2.3(1.2$ to 4.3$) \ddagger$ & $5(9)$ & $15(29)$ & $1.1(0.4$ to 3.0$)$ & 0.23 \\
\hline Rest of lower leg (82300-82399, S824-S829) & $3(5)$ & $6(9)$ & $1.5(0.4$ to 5.9$)$ & $6(7)$ & $7(11)$ & $2.8(1.0$ to 8.1$)$ & 0.47 \\
\hline Feet $(82500-82509,82600-82609,82799$, S920-S929) & $6(7)$ & $12(13)$ & $1.5(0.6$ to 4.0$)$ & $6(9)$ & $11(16)$ & $1.8(0.7$ to 4.8$)$ & 0.79 \\
\hline Total (all of above) & $81(134)$ & $138(226)$ & 1.8 (1.3 to 2.3$) \ddagger$ & $64(119)$ & $208(405)$ & $1.0(0.8$ to 1.3$)$ & 0.006 \\
\hline
\end{tabular}

*Number of subjects with at least one fracture; number in parentheses is total number of discharges with fracture.

tComparison of relative rate before and after surgery. If $\mathrm{P}<0.05$ surgery significantly influenced the risk of fractures in cases compared with controls (Poisson regression).

$\ddagger \mathrm{P}<0.05$, Mantel-Haenszel $\chi^{2}$.

person years (7 to 9) in controls. After surgery, the crude fracture rate was $33 / 1000$ in cases (27 to 39) and $34 / 1000$ (30 to 37) in controls. The risk of fracture was not increased more than 10 years before surgery. In the 6-9 years before surgery, the relative risk of fracture increased greatly, peaking at 5-6 years before surgery. The increase in risk was smaller but still significant in the last five years before surgery. The relative rate of fracture in the patients in the 5-9 years before surgery was significantly higher than in the five years before surgery $(\mathrm{P}=0.001$ by Poisson regression). Within the first year after surgery there was still a significant increase in fracture rate, but the increase disappeared after this period (relative rate 2.0 for $<1$ year $v 0.8$ for $1-9$ years after surgery, $\mathrm{P}=0.003)$. However, more than 10 years after surgery, the risk of fracture increased again (1.7 for fractures $>10$ years after surgery $v 0.8$ for $1-9$ years after surgery, $\mathrm{P}=0.002$ ). This increase was mainly due to an increased number of fractures of the distal forearm (relative rate 2.9, 95\% confidence interval 1.3 to 6.7 ).

After surgery, only age, female sex, and at least one fracture before surgery were associated with increased risk of fracture (table 3). Serum calcium concentrations before and after surgery were not related to risk of surgery.

Table 3 Risk factors for fractures before and after surgery among cases with primary hyperparathyroidism

\begin{tabular}{lcc} 
Risk factor & Before & After \\
\hline Age (years) & $1.02(1.00 \text { to } 1.04)^{*}$ & $1.03(1.02 \text { to } 1.05)^{*}$ \\
\hline Diagnosis (hyperplasia/adenoma) & $0.90(0.41$ to 1.96$)$ & $1.15(0.49$ to 2.68$)$ \\
\hline Fracture before surgery (yes/no) & - & $2.16(1.34 \text { to } 3.48)^{*}$ \\
\hline Sex (male/female) & $0.62(0.34$ to 1.12$)$ & $0.37(0.21 \text { to } 0.64)^{*}$ \\
\hline Kidney stones before surgery (yes/no) & $0.77(0.44$ to 1.33$)$ & $0.63(0.33$ to 1.21$)$ \\
\hline Weight of removed parathyroid tissue $(\mathrm{g})$ & $1.16(0.73$ to 1.85$)$ & $0.94(0.80$ to 1.10$)$ \\
\hline${ }^{*} \mathrm{P}<0.05$ by Poisson regression. & &
\end{tabular}

The contact frequency due to a diagnosis of osteoporosis (international classification of disease (ICD-8): 723.09, ICD-10: M80.0-M80.9 + M81.0M81.9) was also higher in patients than in controls before surgery (relative rate 3.7, 95\% confidence interval 2.2 to 6.5 ) but not after (1.4, 0.7 to 2.7). The increase in risk of osteoporosis before surgery was present only in the year before surgery.

\section{Discussion}

Increase in overall fracture risk

We found an increased risk of fractures of the forearms, the vertebrae, and the lower legs in a series of 674 unselected patients with primary hyperparathyroidism before surgery. It is unlikely that the presence of fractures influenced the decision to operate as virtually all patients at these centres have surgery after diagnosis of primary hyperparathyroidism. Only the few patients who are medically unfit do not have surgery-for example, those with severe cardiac disease.

We found no increase in risk of fracture more than 10 years before surgery, but the risk increased in the 5-10 years before surgery. A smaller increase in risk of fracture was also present in the five years before surgery. The increase in crude risk of fracture in both cases and controls after surgery was due to the increase in age of the cohort and thus in general risk of fracture.

Abnormal parathyroid tissues may have started growing up to 10 years before surgery. The enhanced effect of parathyroid hormone on the skeleton will increase bone turnover, leading to a loss of bone min$\mathrm{eral}^{18}$ that presents as the initial increase in fracture risk. However, this initial resorption of bone will be followed by formation of new bone, and a new steady state between resorption and formation will be reached, although at a reduced bone mineral density. ${ }^{18}$ 
This steady state presents as the period with a stable, but less pronounced, increase in risk of fracture.

The increase in risk of fracture disappeared less than a year after surgery, suggesting a quick restoration of bone biomechanical competence. This finding agrees with studies showing restoration of bone turnover $^{18}$ and a gain in bone mineral after surgery. ${ }^{8}$ The finding that age, female sex, and previous fractures were related to risk of fracture agrees with findings in the general population. ${ }^{19}$

\section{Selection bias}

Our results could have been affected by selection bias. The increased frequency of fractures before, but not after, surgery may be caused by primary hyperparathyroidism but could also reflect the fact that patients had primary hyperparathyroidism diagnosed while being examined and treated for a fracture. This factor would, however, account for only some of the increase because almost all patients had surgery within a year after diagnosis. The increase in fractures was present up to 10 years before surgery-that is, before primary hyperparathyroidism was diagnosed or even suspected.

Another potential bias arises because many spine fractures are symptomless and discovered on spine radiography. ${ }^{20}$ An increased awareness in patients with primary hyperparathyroidism of the possibility of skeletal disease may have led to a higher rate of diagnosis of otherwise symptomless spine fractures by radiography; this is comparable with the increased frequency of diagnosis of osteoporosis in the year before surgery. In a recent study of 407 patients with primary hyperparathyroidism with a mean follow up of 14 years, Khosla et al found an increased frequency of fractures (especially of the vertebrae, distal forearm, ribs, and pelvis) after the diagnosis was established, but only $23 \%$ of the patients in their study ultimately had surgery. ${ }^{16}$ The increased fracture risk in that study may reflect the increased risk of vertebral and forearm fractures seen before surgery in our study. These findings support suggestions that surgery prevents fractures even in mildly hypercalcaemic patients.

\section{Fracture type}

The absence of an increase in fractures of the distal forearm before surgery contrasts with the findings of two other studies. ${ }^{12}{ }^{13}$ However, we found an increase in fractures of the shaft and proximal parts of the forearms. Our finding that fractures of the femoral neck were not increased agrees with the results of Larsson et a ${ }^{15}$ but not with those of Peacock et al, ${ }^{12}$ who reported an increased prevalence of femoral neck fractures at the time of surgery. Khosla et al found a nonsignificant trend towards an increased frequency of proximal femoral fractures. ${ }^{16}$ In agreement with Melton et al we found an increase in risk of fracture before, but not after, surgery.1 ${ }^{11}$ However, our study group was considerably larger than those of Melton et al $(\mathrm{n}=90)$ and Larsson et al $(\mathrm{n}=39)^{13}$ and dealt with all fracture types.

We found an increased risk of fracture of the distal forearm more than 10 years after surgery. This finding is compatible with studies that show a lasting deficit in forearm bone mineral density ${ }^{38}$ and suggests that patients should have their bone mineral density measured after surgery to determine what preventive measures are needed.
What is already known on this topic

Patients with primary hyperparathyroidism have an increased risk of fracture

No studies have evaluated the risk of fracture before and after surgery

\section{What this study adds}

Cases had an increased risk of fracture risk up to 10 years before surgery compared with controls

Risk of fracture was independent of serum calcium concentrations

The risk returned to the level of controls within one year after surgery

The increase in the rate of spinal fractures before surgery reported by Peacock et al was higher than in our study (relative rate $6.9 v 3.5) .{ }^{12}$ Unfortunately, they did not report on adenoma weight or other descriptive factors, precluding a comparison with our data. Because we examined the risk of fractures at many sites, one or more of the results could be significant due to chance. However, our results were consistent with the findings of previous studies on changes in bone mineral density. As the increase in risk of fracture was only modest in the last few years before surgery, it would take a large study sample to show a significantly increased risk of fractures. This may explain why a study of 174 patients did not find an increased risk of spinal fractures. ${ }^{2}$

Contributors: PV drafted the paper and analysed the data. CLM, PC, and MB-T operated on the patients. LM was responsible for clinical control of the patients. VGF coordinated the data collection. All authors participated in the collection, analysis, and interpretation of data and in writing the paper. PV is the guarantor.

Funding: Eli Lilly Osteoporosis Research Fund.

Competing interests: None declared.

1 Wishart J, Horowitz M, Need A, Nordin BE. Relationship between forearm and vertebral mineral density in postmenopausal women with primary hyperparathyroidism. Arch Intern Med 1990;150:1329-31.

2 Wilson RJ, Rao S, Ellis B, Kleerekoper M, Parfitt AM. Mild asymptomatic primary hyperparathyroidism is not a risk factor for vertebral fractures. Ann Intern Med 1988;109:959-62.

3 Elvius M, Lagrelius A, Nygren Å, Alveryd A, Christensson TAT, Nordenström J. Seventeen years follow-up study of bone mass in patients with mild asymptomatic hyperparathyroidism some of whom were operated on. Eur J Surg 1996;161:863-9.

4 Leppla DC, Snyder W, Pak CY. Sequential changes in bone density before and after parathyroidectomy in primary hyperparathyroidism. Invest Radiol 1982;17:604-6.

5 Christiansen P, Steiniche T, Brixen K, Hessov I, Melsen F, Heickendorff L, et al. Primary hyperparathyroidism: effect of parathyroidectomy on regional bone mineral density in Danish patients. A three year follow-up study. Bone 1999:25:589-95.

6 Silverberg SJ, Gartenberg F, Jacobs TP, Shane E, Siris E, Staron RB, et al. Increased bone mineral density after parathyroidectomy in primary hyperparathyroidism. J Clin Endocrinol Metab 1995;80:729-34.

7 Silverberg SJ, Shane E, Jacobs TP, Siris E, Bilezikian JP. A 10-year prospective study of primary hyperparathyroidism with or without parathyroid surgery. N Engl J Med 1999;341:1249-55.

8 Martin P, Bergmann P, Gillet C, Fuss M, Corvilain J, van Geertruyden J. Long-term irreversibility of bone loss after surgery for primary hyperparathyroidism. Arch Intern Med 1990;150:1495-7.

9 Rao DS, Wilson RJ, Kleerekoper M, Parfitt AM. Lack of biomechanical progression or continuation of accelerated bone loss in mild asymptomatic primary hyperparathyroidism: evidence for biphasic disease course. J Clin Endocrinol Metab 1988;67:1294-8.

10 Kenny AM, MacGillivray DC, Pilbeam CC, Crombie HD, Raisz LG. Fracture incidence in postmenopausal women with primary hyperparathyroidism. Surgery 1995;118:109-14. 
11 Melton LJ, Atkinson EJ, O'Fallon WM, Heath H. Risk of age-related fractures in patients with primary hyperparathyroidism. Arch Intern Med 1992;152:2269-73.

12 Peacock M, Horsman A, Aaron JE, Marshall DH, Selby PL, Simpson M. The role of parathyroid hormone in bone loss. In: Christiansen C, Arnaud CD, Nordin BEC, Parfitt AM, Peck WA, Riggs BL, eds. Osteoporosis. Glostrup: Department of Clinical Chemistry, Glostrup Hospital, sis. Glostrup:
1984:463-7.

13 Larsson K, Lindh E, Lind L, Persson I, Ljunghall S. Increased fracture risk in hypercalcemia: bone mineral content measured in hyperparathyroidism. Acta Orthop Scand 1989;60:268-70.

14 Kochersberger G, Buckley NJ, Leight GS, Martinez S, Studenski S, Vogler J, et al. What is the clinical significance of bone loss in primary hyperparathyroidism? Arch Intern Med 1987;147:1951-3.

15 Larsson K, Ljunghall S, Krusemo UB, Naessen T, Lindh E, Persson I. The risk of hip fractures in patients with primary hyperparathyroidism: a population-based cohort study with a follow-up of 19 years. J Intern Med 1993;234:585-93.
16 Khosla S, Melton III LJ, Wermers RA, Crowson CS, O'Fallon WM, Riggs BL. Primary hyperparathyroidism and the risk of fracture: a populationbased study.J Bone Mineral Res 1999;14:1700-7.

17 Mellemgaard A, Jørgensen J. Sygdomsmonstret for indlagte patienter og ambulante patienter 1995. Sundhedsstatistikken 1997:5. Copenhagen: National Board of Health, 1997:1-271.

18 Christiansen P, Steiniche T, Brixen K, Hessov I, Melsen F, Heickendorff L, et al. Primary hyperparathyroidism: short term changes in bone remodeling and bone mineral density following parathyroidectomy. Bone 1999;25:237-44

19 Cummings SR, Nevitt MC, Browner WS, Stone K, Fox KM, Ensrud KE, et al. Risk factors for hip fracture in white women. Study of Osteoporotic Fractures Research Group. N Engl J Med 1995;332:767-73.

20 Black DM, Cummings SR, Kerpf DB, Cauley JA, Thompson DE, Nevitt $\mathrm{MC}$, et al. Randomised trial of effect of alendronate on risk of fracture in women with existing vertebral fractures. Lancet 1996;348:1535-41.

(Accepted 11 June 2000)

\title{
Mortality in joggers: population based study of 4658 men
}

\author{
Peter Schnohr, Jan Parner, Peter Lange
}

Copenhagen City Heart Study, Bispebjerg University Hospital, DK-2400

Copenhagen NV,

Denmark

P Schnohr

chief cardiologist

Department of

Biostatistics,

University of

Copenhagen,

DK-2200

Copenhagen N,

Denmark

J Parner

statistician

Department of

Respiratory Disease,

Hvidovre University

Hospital, DK-2650

Hvidovre, Denmark

P Lange

chief physician

Correspondence to:

P Schnohr

peterschnohr@

dadlnet.dk

BMJ 2000;321:602-3
Since 1970 jogging has become an increasingly popular form of exercise, but the public's concern over its harmful effects has been raised following reports of deaths during jogging. During the past two or three decades the number of joggers and jogging races has increased further, prompting an interest in mortality of joggers.

\section{Participants, methods, and results}

The Copenhagen city heart study is a prospective population study of cardiovascular disease in 19698 men and women aged 20 years and over randomly selected from the population of Copenhagen. ${ }^{1}$ Overall, 4658 men (response rate 72\%) aged 20-79 years with no prior myocardial infarction attended two examinations-one in 1976-8 and the other in 1981-3. Jogging status was ascertained by asking the participants whether they were joggers. The cohort was followed until 30 November 1998. Information about deaths was obtained from the Danish national population register, which is almost $100 \%$ complete.

We observed a major trend in jogging habits over the five year period between the first and second examination. At the first examination, 217 (4.7\%) men reported active jogging. Of these, 96 (2.1\%) were still actively jogging five years later. Between the two examinations, $106(2.3 \%)$ started jogging, showing an almost constant number of joggers. Overall, 4335 men were non-joggers at both examinations. Crude estimates of death rates showed a higher mortality among non-joggers and a lower mortality among persistent joggers.

An analysis of the influence of jogging on time to death was conducted by using a Cox proportional hazards regression model, with age as the time axis. ${ }^{2}$ In addition to jogging, the model included diabetes, smoking, household income, education, and alcohol consumption as potential confounding variables, and systolic blood pressure, concentrations of plasma total cholesterol and plasma high density lipoprotein cholesterol, and body mass index as intermediate variables. A significant effect of jogging was found only for the group that were joggers at both examinations, with an estimated relative risk of 0.37 (95\% confidence interval, 0.19 to $0.71 ; \mathrm{P}=0.003)$. Jogging was therefore included as a binary variable in the final model: persistent jogging or no jogging or jogging at only one of the two examinations. The relative risk of death in persistent joggers was significantly lower than that in non-joggers or those who jogged at only one of the two examinations $(0.39,0.19$ to $0.73 ; \mathrm{P}=0.005)$ (table). Similar results were found when including only potential confounding variables.

\section{Comment}

Regular jogging is not associated with increased mortality in men, as shown by the significantly lower mortality in joggers than non-joggers in our study. The lower mortality of joggers could be an effect of the physical training, but it could also be due to other life-

Jogging and relative risk of death*

\begin{tabular}{lcc} 
& $\begin{array}{c}\text { Relative risk of death } \\
\mathbf{( 9 5 \%} \mathbf{~ C l})\end{array}$ & P value \\
\hline Jogging at examination: & 1.0 \\
\hline No or only at one & $0.39(0.19$ to 0.73$)$ & \\
\hline At both & 1.0 & \\
\hline Diabetes: & $1.75(1.58$ to 1.92$)$ & \\
\hline No & & \\
\hline Yes & \\
\hline
\end{tabular}

Smoking:

\begin{tabular}{lcc}
\hline No & 1.0 & \\
\hline Yes & $1.74(1.57$ to 1.91$)$ & $<0.001$
\end{tabular}

\begin{tabular}{lcc} 
Yes & $1.74(1.57$ to 1.91$)$ & $<0.001$ \\
\hline Household income & 1.0 & \\
\hline Middle or high & $1.21(1.09$ to 1.33$)$ & $<0.001$
\end{tabular}

\begin{tabular}{lcl}
\hline Low & $1.21(1.09$ to 1.33$)$ & $<0.001$ \\
\hline Education: & & \\
\hline$<10$ years & 1.0 &
\end{tabular}

\begin{tabular}{lcc}
$<10$ years & 1.0 & \\
\hline$\geqslant 10$ years & $0.91(0.82$ to 0.99$)$ & 0.04 \\
\hline
\end{tabular}

\begin{tabular}{lcc}
\hline Alcohol consumption per week: & \\
\hline$<21$ drinks & 1.0 & \\
\hline Abstainers & $1.16(1.01$ to 1.32$)$ & 0.03 \\
\hline$>21$ drinks & $1.35(1.19$ to 1.53$)$ & 0.001
\end{tabular}

*Intermediate variables were systolic blood pressure, concentration of plasma total cholesterol and plasma high density lipoprotein cholesterol, and body mass index. Relative risks (from Cox regression model) are shown only for categorical variables.

†Two tailed. 